\title{
Biblioteca del Estudiante Universitario
}

\begin{abstract}
$\mathbf{A}$ N'TONIO Acevedo Escobedo reseñó en el número 3 de la RevisTA IbEROAMERICANA los diez primeros volúmenes de la "Biblioteca del Estudiante Universitario" publicados por la Universidad Nacional Autónoma de México en el año 1939. Ya están en manos de su público y a la venta en las librerías los volúmenes correspondientes a 1940 y casi todos los del año 1941. Muy pronto una pequeña biblioteca de treinta títulos alineará en el estante estudiantil buena parte de lo más escogido entre la producción literaria de México, desde los días anteriores a la conquista hasta los inmediatos que precedieron a la generación militante. Con rapidez y exactitud ha venido realizándose el propósito inicial de esta colección llamada a ocupar un puesto importantísimo no sólo en las bibliotecas escolares sino en todas las del continente, por darnos, en forma elegante y bien escogida, la mejor introducción práctica al conocimiento de una de las literaturas más ricas y más vivaces que el genio hispanoamericano ha producido. Con plan diferente al que presidió en Colombia la formación de la ya famosa colección de Samper Ortega, o, recientemente, en el Perú, la de Ventura García Calderón, que se ha detenido en los primeros doce tomos (trece en realidad, por estar dividido uno de ellos en dos volúmenes), admirablemente impresa en los talleres belgas de Santa Catalina, de Brujas, la colección universitaria mexicana tiene ya su fisonomía propia, y ha de ser, ahora y en lo futuro, muy buscada. La impresión clara y elegante de estos libros, sobriamente ilustrados con dibujos de Julio Prieto o alguna vez con reproducciones de grabados antiguos, y encomendados, cada uno, a personalidades de bien ganada notoriedad en las letras de
\end{abstract}


México, les da rango, y su precio económico los pone al alcance de todos. Sabido es que, en cada diez volúmenes, los correspondientes a un año, se cuentan tomos correspondientes a las diversas épocas literarias, en proporción constante. Pero mejor que toda indicación vaga dará idea la lista de ellos, con los de sus nuevos editores, que es como sigue:

1940.-Poesía indigena de la Altiplanicie (Angel María Garibay K.) ; Crónicas de Michoacán (Federico Gómez de Orozco); Carlos de Sigüenza y Góngora, Relaciones históricas (Manuel Romero de Terreros); Sor Juana Inés de la Cruz, Los empeños de una casa (Julio Jiménez Rueda); J. J. Fernández de Lizardi, El Pensador Mexicano (Agustín Yáñez) ; Juan Bautista Morales, El Gallo Pitagórico (Mauricio Magdaleno); Guillermo Prieto, Musa callejera (Francisco Monterde); Ignacio M. Altamirano, Aires de México (Antonio Acevedo Escobedo); Joaquín Arcadio Pagaza, Selva y mármoles (Gabriel Méndez Plancarte); Manuel Gutiérrez Nájera, Cuentos, crónicas y ensayos (Alfredo Maillefert).

1941.-Libro de Chilam Balam de Chumayel (Antonio Mediz Bolio); Fray Bartolomé de las Casas, Doctrina (Agustín Yáñez); Bernardo de Balbuena, Grandeza mexicana (Francisco Monterde); Gabino Barreda, Estudios (José Fuentes Mares); José Tomás de Cuéllar, La linterna mágica (Mauricio Magdaleno); José María Roa Bárcena, Relatos (Julio Jiménez Rueda) ; José Peón y Contreras, La hija del rey (Ermilo Abreu Gómez). 1

Adviértase desde luego, que muchos de estos títulos corresponden a obras hoy difícilmente asequibles. Alguna es del todo nueva, como ocurre con la versión de las antiguas poesías mexicanas, realizada por don Angel M. Garibay K., bien conocido por sus estudios en ese importantísimo sector, que van renovando el conocimiento de aquella literatura, de que sólo existían, fragmentariamente, versiones más o menos fieles como las de Rojas sobre los cantos recogidos por el $P$. Sahagún, o vulgarizaciones hechas a través de otros traslados, como las inspiradas en Brinton; o interpretaciones libres, como las de José Joaquín Pesado, que dan, acaso, la nota más interesante en la obra total de este poeta neoclásico tan elogiado por Menéndez y Pelayo. Lo reunido, en suma, por Rubén M. Campos, en su libro La producción literaria de los Aztecas (1936), o lo publicado en el 
tomo $\mathrm{V}$ de la edición reciente (1938) de la Historia general de las cosas de Nueva España, de Fray Bernardino de Sahagún, o lo transcrito en más breves páginas por Luis Castillo Ledón o Bernardo Ortiz de Montellano.

El libro del P. Garibay, precedido de otros trabajos suyos, en folletos agotados o páginas de revista, tiene, pues, un interés muy vivo. No cae su autor en la tentación de presentar sus tradiciones como reflejo de las joyas más sublimes de una poesía hasta aquí ignorada; pero sabe bien que podemos "percibir en muchos puntos su belleza y su valor informativo acerca de las ideas y sentimientos de aquellos poetas", cantos anónimos, o de atribución dudosa, y muchas veces oscuros en su expresión; lo cual no es para amedrentar a los lectores de poesía en los días que corren. Contentándonos con lo que se percibe encontramos en las versiones de este libro, muestra de una labor mucho más extensa y minuciosa, inédita todavía en gran parte, esos fulgores repentinos que denuncian la poesía verdadera. En la de estos cantores se advierte una melancolía por lo fugaz de la existencia, un anhelo de inmortalidad, que vuelven constantemente como obsesión difícil de esquivar.

A1 lado de estos cantos aztecas El libro de Chilam Balam de Chumayel, en la traducción publicada años ha por Antonio Mediz Bolio y ahora revisada y corregida por su autor, nos ofrece un aspecto de la cultura maya', y su visión mística y poética del mundo, con sus profecías y fórmulas mágicas, lleno de atractivo, si no para hallar en él nuevas fuentes de sensibilidad, para satisfacer o despertar curiosidades en los aficionados a las formas pretéritas del pensamiento y del arte. Ilustraciones tomadas de los códices originales intercálanse en el texto, que en su vestidura de habla española denuncia la mano del poeta que los ha trasladado.

La literatura colonial se ilustra en las series que reseñamos con los textos reunidos en el volumen de Crónicas de Michoacán por la mano experta de don Federico Gómez de Orozco, tan importantes para el conocimiento de la vida privada de los pobladores primitivos y de las fundaciones religiosas; con las relaciones de Sigüenza y Góngora, portento de erudición, considerado en sus días como árbitro del saber y del gusto, por cuyas páginas se ha entrado valientemente don Manuel Romero de Terreros; con la comedia 
de enredo Los empeños de una casa, en que brilla el ingenio de Sor Juana Inés con menores quilates que en sus maravillosas poesía's (de las cuales es de esperar que algún día se halle muestra en esta colección con arreglo a la estimación que en nuestros dias las levanta por encima de toda la obra lírica contemporánea); con un Ideario de Las Casas, recopilado entre sus escritos por Agustín Yáñez, para situar esta gran figura, tan discutida en sus tiempos como ahora exaltada o discutida también (recuérdense las acusaciones de superchería que lanzara en contra suya el doctor Rómulo D. Carbia), en un monumento más persistente que bronces y mármoles como corresponde al que el prologuista considera como "uno de los sumos Padres y Doctores de América", y, por fin, con la Grandeza mexicana y fragmentos de otros libros de Bernardo de Balbuena, ilustrados por Francisco Monterde, que dirige la impresión de estos libros con tino y gusto excelentes.

E1 hecho de ser españoles los dos autores últimamente citados (y algunos de los cronistas de Michoacán) recalca el propósito, ya manifiesto desde la primera serie, de no limitar el campo de la "Biblioteca del Esstudiante Universitario" a los nacidos en México, admitiendo en sus índices a los que, venidos de ultramar, hicieron obra de sentido mexicano; "la Grandeza mexicana, dice Francisco Monterde, pertenece a nuestra literatura, tanto como a la de España": buen trueque por la consideración que España presta, como a producto propio de sus letras, al teatro de Ruiz de Alarcón. Ni Esspaña quiere arrebatárselo a México, ni México podria arrebatárselo a España. Viendo estamos, pues, que el caso no es único, y que su planteamiento, como tema de historia literaria, no admite solución radical, pero tampoco la necesita. El perfil mexicano en Alarcón, así como la adquirida mexicanidad de Balbuena, serán, sin duda, rasgos que habrá de tener en cuenta la estimativa al juzgarlos en toda su talla.

Entre los libros que corresponden al México independiente pasamos con facilidad de El Pensador Mexicano, preferido aquí en su obra de periodista sobre la de novelador y padre del Periquillo Sarniento (que Menéndez y Pelayo declaraba no conocer), a $E l$ Gallo Pitagórico, de Juan Bautista Morales; y el tránsito no es difícil. El costumbrismo es la vestidura de ambos; la política late en el 
fondo. Periodismo en ambos, como en alguno de los narradores que nos aproximan los restantes volúmenes y hasta en alguno de los poetas: es decir, en Guillermo Prieto. No cabe olvidar que mucha de la producción literaria del siglo pasado se escribe para el periódico, intermediario, antes que el libro, o único en tantos casos, por el cual el escritor se comunica con el público. De aquí la abundancia del relato breve, de la "novela corta", del cuento. De la narración que empieza y termina en la hoja volandera del diario o en el cuaderno liviano de la revista. Literatura y periodismo conviven, $\mathrm{y}$ las prensas periódicas recogen los primeros frutos de muchos ingenios, para dejarlos morir entre sus páginas o para guardarlos mientras una atención cuidadosa, si no el impulso del propio autor, va a buscarlos para darles la supervivencia más probable del volumen. $Y$ es el escrito destinado al periódico, la palpitación más viva de una actualidad en la que pueden hallarse dotes de per, sistencia, y quién sabe si de inmortalidad. El periódico viene a ser una especie de borrador, por desgracia, con el progreso de los medios mecánicos, cada vez más expuesto a imperfecciones. iQuién sabe cuántas son las erratas llamadas a perpetuarse, los párrafos o líneas caídos en las publicaciones actuales dentro de las páginas escogidas para no perecer en los columnas donde vieron la luz primera!

Aun en textos recientes, y no de periódicos, por ejemplo, en el drama de Peón y Contreras, La hija del rey, aunque cuidadosamente revisado, se echan de ver determinadas imperfecciones (algún verso que no consta, alguna redondilla incompleta) atribuibles, probablemente, a la pobreza con que solian imprimirse en el siglo XIX las obras dramáticas.

Por lo demás, el carácter de ese drama expresa muy bien el romanticismo mesurado que reina, después de las primeras exaltaciones de la generación triunfante y antes de las exageraciones de la pléyade en que se marca la descomposición del género, cuyo mejor representante es Echegaray, en el teatro de habla española; esto es, en aquel teatro cuyos más claros ejemplos van desde el Don Francisco de Quevedo, de Florentino Sanz, hasta El haz de leña, de Núñez de Arce.

De los poetas vienen a estas dos series la Musa callejera de Guillermo Prieto, a que ya se aludió arriba, y que es, probablemente, 
el ejemplo mejor de ese género, cuyos prototipos pueden verse, con todas las distancias entre uno y otro, en el francés Béranger y en el español Trueba, y como si se hubiera buscado el más vivo contraste, la recopilación de versos originales y traducidos del obispo Pagaza, que se agrupan con el título de Selva y mármoles, selección especialmente feliz que nos da los dos aspectos de este neoclasicismo robusto y sapiente, inspirado en el paisaje concreto y robustecido con el recuerdo del atavío literario, que con tanta holgura supo pedir prestado el autor, al traducirlos en sonoras estrofas, a Virgilio y a Horacio: la calle y la academia, los dos campos de inspiración de una poesía que ya se apartaba de las aulas románticas y no entraba aún en los jardines del modernismo.

Uno de los tomos está dedicado a Gutiérrez Nájera, pero no al poeta precursor, de fisonomia tan interesante, y que también, por algunas facetas, puede enlazarse con la poesía del período anterior, superado por él, sino al narrador, igualmente interesante, en cuanto a estilo y manera, en contraste con los relatos de un Cuéllar, de un Roa Bárcena. Se ha señalado la circunstancia de que en el tomo se incluye un artículo juvenil del "Duque Job" que no es sino copia de otro del erudito hispano José María Sbarbi, al que fué a dar el recopilador por una circunstancia fortuita $y$, en última instancia, afortunada, puesto que permite descartar de la obra del escritor algo que no es suyo, aunque como tal figure. Señaló aquel artículo como el primero publicado por Gutiérrez Nájera un benemérito erudito americano, Mr. Erwin K. Mapes, y ha descubierto el plagio -probablemente sin más alcance que una travesura de mocedadel doctor Alfonso Méndez Plancarte, hermano del autor del prólogo a Pagaza que bien podría señalarse como ejemplar entre los que sirven de introducción a estos volúmenes, aunque sólo fuera por la anotación y la cuidadosa bibliografía, que sería necesaria en todos para dejar así en manos del estuđiante, a quien por definición están destinados los libros de esta "Biblioteca", los principales elementos que pueden ayudarle a perfeccionar su conocimiento del autor que prefiera. Pero bien puede alabarse en todos ellos alguna cualidad: ya el entusiasmo con que se intenta destacar la figura del autor, ya el esfuerzo para situar la obra en el curso de las ideas actuales, ya el primor de evocación (como en el prólogo de Alfredo Maillefert, muerto hace pocos meses, a los Cuentos, crónicas y ensayos de Gutiérrez 
Nájera, nueva muestra de su profunda asimilación azorinesca), ya la penetración crítica que renueva apreciaciones tradicionales. En conjunto, esta "Biblioteca" vendrá a ser, por lo que toca a sus introducciones, la mejor historia monográfica de la literatura mexicana que hasta hoy se haya intentado.

\section{EnRIQUe Díez-Canedo}

\section{NOTA}

1 Posteriormente han aparecido Poesia tomántica (José Luis Martínez y Alí Chumacero); Humanistas del siglo XVIII (Gabriel Méndez Plancarte) y José María Luis Mora, Ensayos, ideas y retratos (Arturo Arnáiz y Freg). 
